\title{
A mini review of dolphin carbohydrate metabolism and suggestions for future research using exhaled air
}

\section{Sam H. Ridgway ${ }^{1,2 *}$}

${ }^{1}$ National Marine Mammal Foundation, San Diego, CA, USA

2 U.S. Navy Marine Mammal Program, Space and Naval Warfare Systems Center Pacific, San Diego, CA, USA

\section{Edited by:}

Stephanie Venn-Watson, National Marine Mammal Foundation, USA

Reviewed by:

Rudy M. Ortiz, University of California Merced, USA

Helena Barbosa Sampaio, State

University of Campinas, Brazil

\section{*Correspondence:}

Sam H. Ridgway, National Marine

Mammal Foundation, 2240 Shelter

Island Blvd., San Diego, CA 92106,

USA

e-mail: sridgway@ucsd.edu
In the 1960s, I explored some aspects of carbohydrate metabolism in healthy bottlenose dolphins (Tursiops truncatus). Their physiological picture resembled what had been described for hyperthyroid diabetics. Dolphins have elevated thyroid hormone turnover, and fasting dolphins maintain a relatively high level of plasma glucose. After dolphins ingest glucose, plasma levels remain high for many hours. Interestingly, plasma glucose must exceed $300 \mathrm{mg} / \mathrm{dL}$ (about twice as high as the human threshold) before glucose appears in urine. Due to their diabetes-like states, trainability, and unique natural respiratory anatomy and physiology, dolphins may offer useful clues to metabolites in the breath that may be used to non-invasively monitor diabetes in humans. Dolphins take very rapid and deep breaths that are four or five times as deep as humans and other terrestrial mammals, making them ideal for physiological assessment using non-invasive exhaled air. Avenues for successfully identifying breath-based markers for metabolic disease and physiology in dolphins can be done with both modern technology and the evolutionarily advantageous canine nose. This review summarizes aspects of dolphin metabolism previously learned and offers new directions for diabetes research that may benefit both dolphin and human health.

Keywords: dolphin, carbohydrate, breath analysis, diabetes, exhalation, glucose, dog, smell

\section{INTRODUCTION}

Bottlenose dolphins (Tursiops truncatus), even as neonates, have very low carbohydrate diets. Dolphin milk contains only about $1 \%$ carbohydrate. During the nursing period of $1-3$ years, the offspring receives large amounts of lipid and protein, but only small amounts of lactose milk sugars. Of the $1 \%$ sugar in dolphin milk, $90 \%$ is lactose, and only minor amounts of glucose and its metabolites are found (1). Once dolphins are weaned, their diet primarily consists of whole fish of various species that yield a diet high in fat and protein and are almost devoid of carbohydrate (2). The normal dolphin diet is in many ways similar to the ketogenic diet of humans (3). Dolphin dietary protein in the whole fish diet, however, yields amino acids whose metabolic effect is primarily glucogenic rather than ketogenic.

Given a whole fish diet, I was surprised to find relatively high fasting blood sugar levels in dolphins (4). We collected blood samples after 14-h fasting periods. Mean \pm SD glucose values for 110 samples from 10 males was $131 \pm 36 \mathrm{mg} / \mathrm{dL}$ and for 121 samples from 11 females, mean glucose was $127 \pm 27 \mathrm{mg} / \mathrm{dL}$. These values for true glucose seemed high, but the findings were consistent in healthy, non-stressed dolphins. One dolphin had several fasting plasma glucose values over $200 \mathrm{mg} / \mathrm{dL}$. Interestingly, concurrent urinalysis showed no rise in urine glucose. The animals had no symptoms of diabetes mellitus such as weight loss, fatigue, or vomiting (a colleague, Dr. David Kenney indicated that he had a diabetic dolphin that he treated with insulin. While the data were never published, Dr. Kenney's personal observation led us to probe further into dolphin carbohydrate metabolism).
Our studies showed that dolphin glucose tolerance curves were prolonged. After we gave an oral glucose load of $1.75 \mathrm{~g} / \mathrm{kg}$ body weight, plasma glucose did not return to baseline levels for many hours. Thus, several of our studies showed a prolonged glucose tolerance curve, mimicking a diabetic response. Interestingly, urine glucose values were not elevated after a glucose load. When enough glucose was given to raise plasma glucose above $300 \mathrm{mg} / \mathrm{dL}$, urine glucose increased. The high threshold for glucose excretion is facilitated by a higher plasma osmolality, which in dolphins, is around $335 \mathrm{mOsm} / \mathrm{L}$ (5). Humans with diabetes mellitus have increased plasma osmolality $(320 \mathrm{mOsm} / \mathrm{L})$ and acid urine, more like dolphins. Thus, the tubular renal threshold for glucose in dolphins is about twice as high as in humans.

During prolonged fasting states, dolphins do not become ketotic. When dolphins were fasted for $72 \mathrm{~h}$, plasma glucose levels remained at pre-fast levels. Even after $72 \mathrm{~h}$, we were not able to sniff acetone or ketone smells in the dolphin breath. Levels of acetone and acetoacetic acid were also not increased in urine. It appeared that dolphins successfully balance protein and lipid metabolism during fasting. As result, glucose is produced by gluconeogenesis in the liver as body protein is metabolized during prolonged fasting. Muscle and other body protein sources were consumed along with body fat (5). Similar lack of ketoacidosis in another marine mammal model, the northern elephant seal, occurs in more extreme circumstances, including 3-month fasting periods (6). Other animal models for diabetes were recently discussed (7). 


\section{DOLPHIN THYROID}

Thyroid activity changes, including hypo- and hyper-thyroidism have been associated with diabetes in humans (8-10). Hyperthyroid states have been proposed as both the cause of a diabetes-like hyperglycemia and caused by potential injury to pancreatic islet cells. Dolphin thyroid measurements, including plasma levels of thyroxine (T4) and triiodothyronine (T3), have been previously published (5, 11-15). Dolphin T4 levels are slightly higher or similar to human normal values, depending on tests employed, while T3 levels are within the human normal range. Using isotope labeled T3 and T4 injected simultaneously, turnover rates of both thyroid hormones were higher in dolphins than in humans (13). Future research may focus on the potential role and reason of higher thyroid hormone turnover rates in dolphins and associations with hyperglycemia and their natural diabetes-like states. Dolphin T4 levels have been shown to increase after $24 \mathrm{~h}$ of fasting (11).

\section{DOLPHIN DIVING}

In our early studies, immunologically measurable insulin in the blood was low, and plasma insulin was slow to increase after an oral glucose load (5). This negligible insulin response to glucose was different than the hyperinsulinemic response after ingestion of high protein fish diets (15). The lack of increased insulin with elevated glucose in dolphins may be especially important since high insulin levels can inhibit gluconeogenesis, and gluconeogenesis is the source of nearly all glucose from the natural fish diet. Lower insulin levels may have some significance as it relates to a dolphin's diving physiology. Considerable lactate is produced during a dive (16-18). Lactate is well used by the diabetic heart, whereas its glucose utilization is extremely low. When insulin is supplied, the heart increases its utilization of glucose but not of lactate; whereas, brain metabolism of glucose is little affected by insulin (19). Increased lactate consumption by the heart might be advantageous to an animal making frequent dives. The blood glucose level closely follows the lactate level and increases slightly after a dive (20). Trained belugas (Delphinapterus leucas) had marked increases in plasma lactate after trained dives in the open ocean (18).

In another study, trained dolphins made numerous dives in the open ocean. Upon returning from depth, animals exhaled in an underwater funnel before taking a breath at the surface (21). After dives to $200 \mathrm{~m}$ depth, while the dolphin was at the surface just after the dive, we conducted a short study. The animal was signaled to exhale into the funnel on the third, sixth, and ninth breath after dives. After about nine breaths the dolphin was ready to dive again. I interpreted the results to indicate that it took about nine breaths for the dolphin to blow off sufficient $\mathrm{CO}_{2}$ to stay in aerobic metabolism after a $200 \mathrm{~m}$ dive. For deeper dives and longer breath holds, exhaled lung air could reach levels of only $1.5 \% \mathrm{O}_{2}$, suggesting insufficient $\mathrm{O}_{2}$ to maintain aerobic metabolism.

From these results, we concluded that an almost complete anaerobicity exists throughout the animal during the last part of a prolonged dive (21). The very low exhaled $\mathrm{O}_{2}$ data indicated that the brain must also be operating with at least partial reduction in oxygen consumption during the period. Another diving marine mammal, the harbor seal (Phoca vitulina), has an extreme capability for cerebral hypoxia (22). More recently, it was determined that the aerobic dive limit for belugas (Delphinapterus leucas) was about $10 \mathrm{~min}$ while the animals could dive for $18 \mathrm{~min}$ (18). It is known that brain tissue can function anaerobically for a short time if sufficient glucose is available as a substrate for anaerobic metabolism. Therefore, a healthy level of blood glucose is critical for a mammal that can make long dives. This may explain why cetaceans, even as adults, have extremely efficient glucose carrying capacity via GLUT-1 transporters; among adults, this capability was previously thought unique to humans and other primates (23).

\section{RESPIRATORY QUOTIENTS AND METABOLISM OF MONO- AND DI-SACCHARIDES}

The respiratory quotient $\left(\mathrm{RQ}=\mathrm{CO}_{2}\right.$ eliminated $/ \mathrm{O}_{2}$ consumed $)$ is an indicator of metabolic balance, including the relative oxidation of glucose, protein, and fat. In humans, pure carbohydrate oxidation results in the highest RQ (1.0), while pure fat oxidation results in the lower end RQ (0.7) (24). Human studies have demonstrated that administration of glucose increases the RQ (25). To determine effects of ingested glucose on the RQ in dolphins, we studied $\mathrm{CO}_{2}$, and $\mathrm{O}_{2}$ exhaled in the breath following a fed glucose load of $1.75 \mathrm{~g} / \mathrm{kg}$ of body weight. Analysis of the exhaled breath (Figure 1) revealed that the RQ remained close to 0.70 , actually lower than when they are fed fish or fasted for short periods. Future research may explore the adaptive relevance of why dolphins do not have an increased RQ in response to glucose administration, including an apparent lack of an oxidative response.

Disaccharidases are enzymes that break ingested disaccharides (i.e., sucrose, lactose, and maltose) into simpler sugars (monosaccharides, including glucose, fructose, and galactose). In humans, insulin deficiency induces an abnormal increase in intestinal disaccharidases (26). Disaccharidase in the gastrointestinal tract is absent in some species of marine mammals (27). Since dolphin intestinal disacchadridase had not been examined, I decided to test the ability of the dolphin to digest sucrose using the exhaled breath.

Results from sucrose ingestion studies were slightly different from earlier studies using glucose. $\mathrm{CO}_{2}$ in dolphin breath was measured after oral sucrose ingestion ( $1 \mathrm{~kg}$ of sugar in fish). We analyzed dolphin breath after various periods of breath hold and compared sugar-fed days with days when only fish were fed. Multivariate 2-way analyses of variance were used to evaluate differences in $\mathrm{CO}_{2}$ and $\mathrm{O}_{2}$ fraction of air expired, as well as respiratory quotients, by ingestion or no ingestion of sugar. Results are shown in Figures 1B-D. Similar to my findings with ingested glucose, there were no significant differences in $\mathrm{O}_{2}$ or RQ among dolphins that did or did not eat sugar; or by hours after eating sugar. $\mathrm{CO}_{2}$ levels, however, were higher among dolphins that ingested sugar compared to dolphins that did not $(0.06 \pm 0.013$ and $0.05 \pm 0.005$, respectively; $P<0.001$ ). Among human patients, $\mathrm{PaCO}_{2}$ conversely decreased when enteral-fed high fat, low carbohydrate diets, demonstrating that dolphins and humans may have similar increases and decreases in $\mathrm{CO}_{2}$ in response to higher and lower carbohydrate intake (28). Thus, changing $\mathrm{CO}_{2}$ levels with sucrose consumption indicates that dolphins, unlike some marine mammals, can digest complex carbohydrates. This would not 

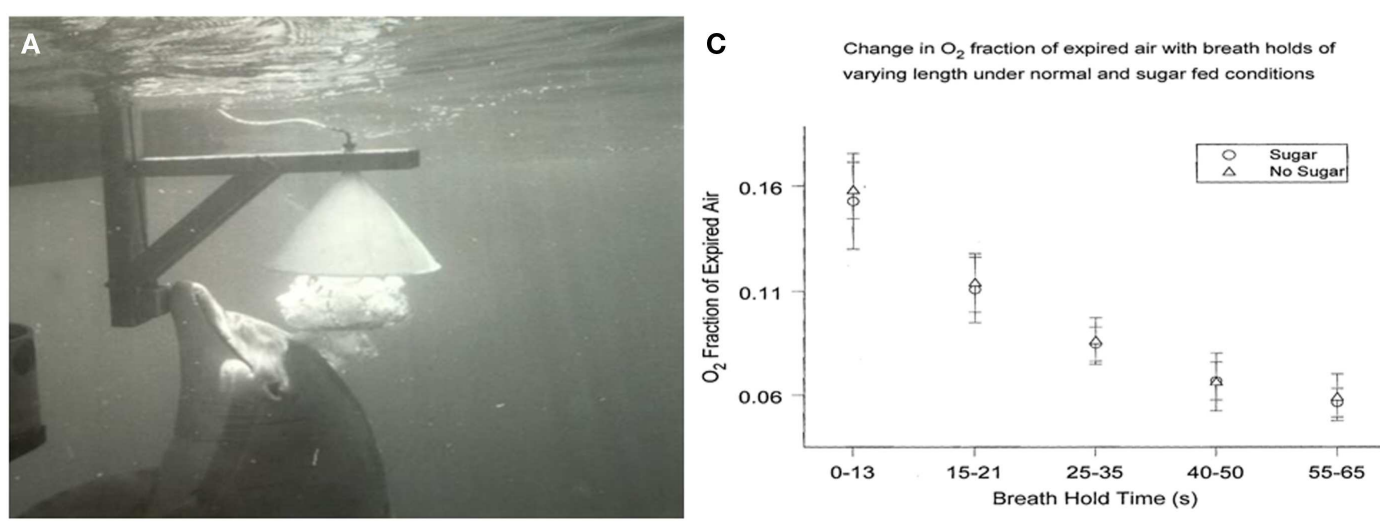

B Change in $\mathrm{CO} 2$ fraction of expired air by time post sugar consumption

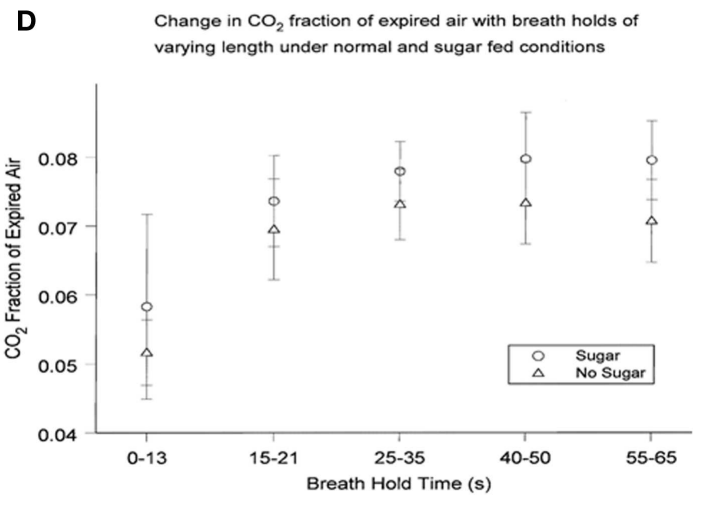

FIGURE 1 | (A) Dolphin exhales, exploding a large bubble into the water-filled collecting funnel. (B) Change in $\mathrm{CO}_{2}$ fraction of exhaled breath from 1 to $4 \mathrm{~h}$ after sugar consumption. Breath holds less that about $15 \mathrm{~s}$ are not as reliable

indicators of $\mathrm{CO}_{2}$ total expired. (C) Change in $\mathrm{O}=$ fraction of expired breath $1-4 \mathrm{~h}$ after sugar consumption. (D) Change in $\mathrm{CO}_{2}$ fraction of expired breath $1-4 \mathrm{~h}$ after sugar consumption.

be unexpected given that dolphins originated from land and their closest terrestrial, ungulate relatives have diets with complex carbohydrates (29).

Single breath samples from dolphins has been studied to further elucidate diving physiology and carbohydrate metabolism. Recently, nitric oxide (NO) levels in dolphin breath have been determined (30).

\section{FUTURE BREATH RESEARCH}

Due to the dolphin's unique respiratory anatomy and their diabetes-like physiology, important results will likely come from dolphin breath and breath condensate measurements (31). Analysis with modern equipment will enable more discriminate detection of compounds linked to changing metabolic states. However, I propose that the intelligence of the canine and its sensitive nose will yield useful data as well.

\section{THE DOLPHIN BREATH}

Dolphins breathe less frequently than terrestrial mammals. They compensate by taking deeper breaths, and they extract more oxygen $\left(\mathrm{O}_{2}\right)$ from the breath $(5,32)$. In terrestrial mammals, including humans, lung volume represents about $6 \%$ of body volume irrespective of body weight (33). In bottlenose dolphins that we have studied, total lung volume on a milliliter per kilogram basis is similar to that of humans. Thus, compared to humans, dolphins take in at least four times as much air with each breath. Additionally, dolphins breathe less frequently, take much deeper breaths, and extract more $\mathrm{O}_{2}$ from each lung full of air.

A total of $80 \%$ tidal air was measured in dolphins (32). Dolphins inhale in a fraction of a second, hold the breath for a considerable period then rapidly exhale and inhale again. Their blowhole and robust nasal cavities, with no turbinates or other structures for potential slowing of the air, allow for rapid inhalation through a short robust trachea to the depth of each lung. Dolphins take in air that is almost $21 \% \mathrm{O}_{2}$. At the end of a long breath hold, dolphin exhaled air can contain as little as $1.5 \% \mathrm{O}_{2}$. The alveoli of the dolphin lung are structured for maximum exposure of lung air to blood circulation. The inter-alveolar septa have double capillary beds separated by an elastic-tissue membrane (34). Compared to a single capillary bed in human lung, the dolphin lung may offer a more efficient exchange of $\mathrm{O}_{2}$ and carbon dioxide $\left(\mathrm{CO}_{2}\right)$. In addition, other metabolites can be efficiently exchanged between blood and lung air (35).

\section{COLLECTING DOLPHIN BREATH}

Wondering how to collect the dolphin breath, as I walked beside a dolphin pool, an animal approached me and released a large bubble. This was a common dolphin behavior. They sometimes exhale 

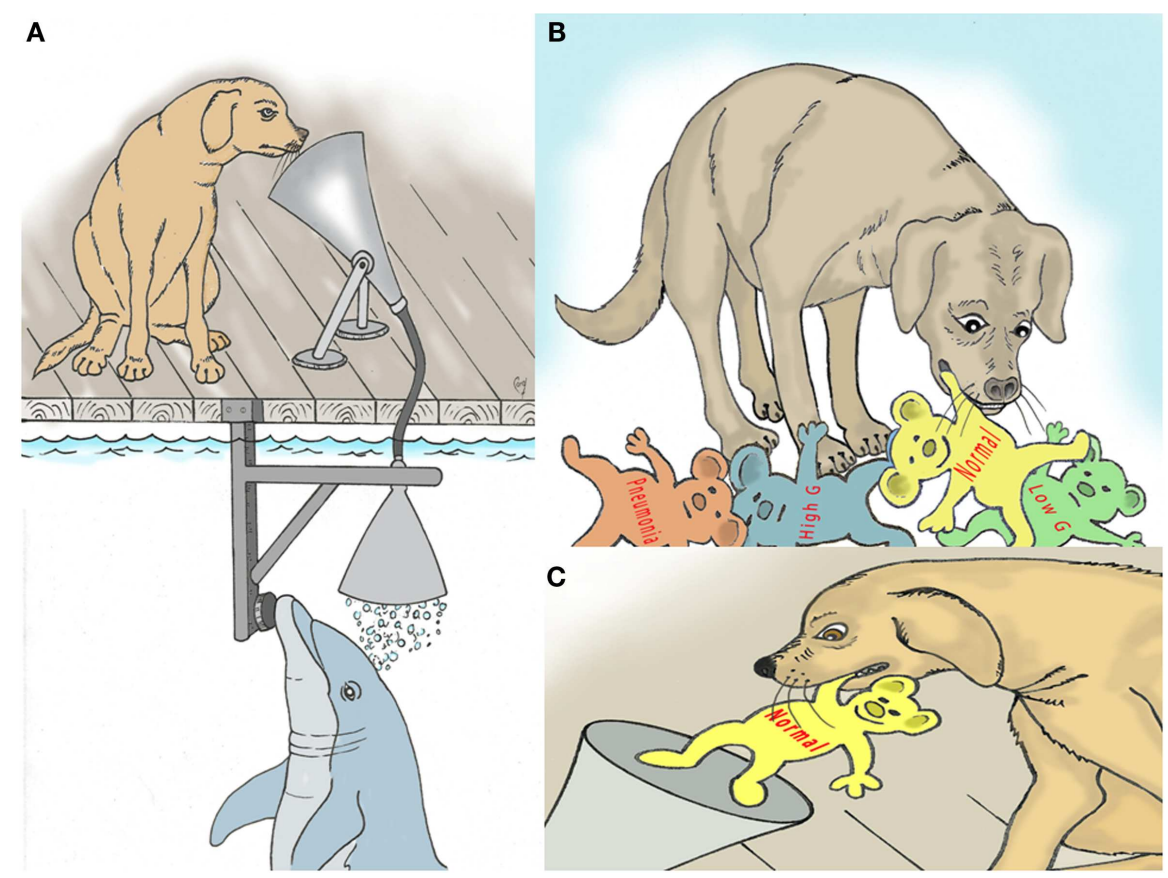

FIGURE 2 | (A) Depiction of trained dog sniffing dolphin breath for assessment of metabolic and disease markers. (B) Dog selects named models that represent various breath markers of metabolism and disease. (C) The selected model is deposited back into the "sniff" funnel to confirm the dog's decision.

large bubbles under aggregations of fish very near the surface. The rising bubble carries some of the fish to the surface immobilizing the fish just long enough for the dolphin to easily take them. For me, the bubble release just below me appeared to be a gesture connected with food (35). Trainers used this natural bubble blowing behavior, and found that dolphins readily exhaled into a large water-filled, underwater funnel $(21,30)$. After an explosive exhalation, dolphin breath displaced the water in a fraction of a second and flowed through tubing for collection and analysis (Figure 1A).

\section{CANINE DETECTORS}

It is well known that canines (dogs) have a very sensitive sense of smell (36). They also have a very good ability to learn the names of numerous different objects $(37,38)$. This cognitive and sensory ability can be melded using techniques employed to train dolphins. Dolphins will exhale into an underwater funnel, the breath with flow up to the dog for detection of breath markers by smell (Figure 2). The dog then goes to pick up a specific marker that has been identified by word and by odor to match a breath marker of interest, for example acetone (Figures 2B,C). Dogs have also been trained to communicate using a keyboard (39). The keyboard capability might also be used.

\section{REFERENCES}

1. Shaw DH. Neutral carbohydrates in the milk of bottlenose dolphin (Tursiops truncatus). Carbohydr Res (1971) 19:419-22. doi:10. 1016/S0008-6215(00)86176-5

2. Wells RS, McHugh KA, Douglas DC, Shippee S, McCabe EB, Barros NB, et al. Feeding and activity patterns of a free-ranging, longresident community of bottlenose dolphins in Sarasota Bay, Florida. Front Endocrinol (2013) 4:139. doi: 10.3389/fendo.2013.00139

3. Freeman JM, Kossoff EH, Hartman AL. The ketogenic diet: one decade later. Pediatrics (2007) 119:535-43. doi:10.1542/peds.2006-2447

\section{ADVANTAGE OF CANINE DETECTORS}

Although sophisticated analysis equipment is available in the laboratory setting, it is not readily adaptable for use at the dolphin locations. For example, seawater is often corrosive to complex electronic equipment. Dolphin breath has been collected in special bags and removed to the laboratory for analysis. In some cases, this may work well (30). In many cases, however the immediate feedback from the canine detector would be invaluable. In addition, canines are quite mobile and can be posted at sea or in remote locations where laboratory support and logistics are difficult.

In summary, while the bottlenose dolphin can have a sustained postprandial hyperglycemia, mimicking diabetes in people, dolphins appear to have many adaptations that enable the benefits of readily available glucose while potentially protecting them against complications of hyperglycemia. Understanding how these mechanisms work may have profound benefits for human health, especially with regard to diabetes.

\section{ACKNOWLEDGMENTS}

I thank Jim Corey for his drawings of the dog sniffing dolphin breath and other dog behaviors. Erika Putman helped with some figures and Stephanie Venn-Watson with statistics of breath sample data.

4. Ridgway SH, Simpson JG, Patton GS, Gilmartin WG. Hematologic findings in certain small cetaceans. J Am Vet Med Assoc (1970) 157: 566-575.

5. Ridgway SH. Homeostasis in the aquatic environment. In: Ridgway SH editor. Mammals of the Sea: Biology and Medicine. Springfield:
Charles C. Thomas (1972). p. 590-747

6. Houser DS, Champagne CD, Crocker DE. A non-traditional model of the metabolic syndrome: the adaptive significance of insulin resistance in fasting-adapted seals. Front Endocrinol (2013) 4:164 doi:10.3389/fendo.2013.00164 
7. Kaplan JR, Wagner JD. Type 2 diabetes - an introduction to the development and use of animal models. ILAR J (2006) 47:181-5. doi:10. 1093/ilar.47.3.181

8. Chubb SAP, Davis WA, Inman Z, Davis TME. Prevalence and progression of subclinical hypothyroidism in women with type 2 diabetes: the Fremantle Diabetes Study. Clin Endocrinol (2005) 62:480-6. doi:10.1111/j.1365-2265. 2005.02246.x

9. Kreines K, Jett M, Knowles HC. Observations in hyperthyroidism of abnormal glucose tolerance and other traits related to diabetes mellitus. Diabetes (1965) 14:740-4.

10. Mitrou P, Boutati E, Lambadiari V, Tsegka A, Raptis AE, Tountas N, et al. Insulin resistance in hyperthyroidism: the role of IL6 and TNF $\alpha$. Eur J Endocrinol (2010) 162:121-6. doi:10.1530/EJE-09-0622

11. Ortiz RM, Long B, Casper D, Ortiz CL, Williams TM. Biochemical and hormonal changes during acute fasting and re-feeding in bottlenose dolphins (Tursiops truncatus). Mar Mamm Sci (2010) 26:409-19. doi:10.1111/j.17487692.2009.00309.x

12. Ridgway SH, Patton GS. Dolphin thyroid: Some anatomical and physiological findings. $Z \mathrm{Vgl}$ Physiol (1971) 71:129-141.

13. St Aubin DJ, Ridgway SH, Wells RS, Rhinehart H. Dolphin thyroid and adrenal hormones: circulating levels in wild and semidomesticated Tursiops truncatus, and influence of sex, age, and season. Mar Mamm Sci (1996) 12:1-13. doi:10.1111/j.17487692.1996.tb00301.x

14. Sterling K, Milch PO, Ridgway SH. The day of the dolphin: thyroid hormone metabolism in marine mammals. In: Harland WA, Orr JS editors. Thyroid Hormone Metabolism. New York: Academic Press (1975). p. 241-7.

15. Venn-Watson S, Smith C, Stevenson S, Parry C, Daniels R, Jensen $\mathrm{E}$, et al. Blood-based indicators of insulin resistance and metabolic syndrome in bottlenose dolphins (Tursiops truncatus). Front
Endocrinol (2013) 4:136. doi:10. 3389/fendo.2013.00136

16. Kooyman GL. Diverse Divers: Physiology and Behaviour. Berlin: Springer (1989).

17. Ponganis PJ, Kooyman GL, Ridgway SH. Comparative diving physiology. In: Brubakk $\mathrm{AO}$, Neuman TS editors. Bennett and Elliott's Physiology and Medicine of Diving. London: Harcourt (2003). p. 211-26.

18. Shaffer SA, Costa DP, Williams TM, Ridgway SH. Diving and swimming performance of white whales, $\mathrm{Del}$ phinapterus leucas: an assessment of plasma lactate and blood gas levels and respiratory rates. J Exp Biol (1997) 200:3091-9.

19. Best CH, Taylor NB. The Physiological Basis of Medical Practice. 8th ed. Baltimore: Williams and Wilkins (1967). 1339 p.

20. Scholander PF. Experimental investigations on the respiratory function in diving mammals and birds. Hvalrad Skr (1940) 22:5-131.

21. Ridgway SH, Scronce BL, Kanwisher J. Respiration and deep diving in the bottlenose porpoise. Science (1969) 166:1651-1654.

22. Kerem D, Elsner R. Cerebral tolerance to asphyxial hypoxia in the harbor seal. Respir Physiol (1973) 19:188-200. doi:10.1016/ 0034-5687(73)90077-7

23. Craik JD, Young JD, Chesseman CI. GLUT-1 mediation of rapid glucose transport in dolphin (Tursiops truncatus) red blood cells. Am J Physiol (1998) 274:R112-9.

24. Wrightington $M$. The effect of glucose and sucrose on the respiratory quotient and muscular efficiency of exercise. J Nutr (1942) 24:307-15.

25. Sandstrom K, Larsson LE, Nilsson K, Stenquist O. Intraoperative glucose administration influences respiratory quotient during paediatric anaesthesia. Acta Anaesthesiol Scand (1999) 43:302-7. doi:10. 1034/j.1399-6576.1999.430310.x

26. Liu L, Yu YL, Liu C, Wang XT, Liu XD, Xie L. Insulin deficiency induces abnormal increase in intestinal disaccharidase activities and expression under diabetic states, evidences from in vivo and in vitro study. Biochem Pharmacol (2011) 82:1963-70. doi:10.1016/j.bcp.2011.09.014

27. Ketchmer N, Sunshine P. Intestinal disaccharidase deficiency in the sea lion. Gastroenterology (1967) 53:123-9.

28. Al-Saady NM, Blackmore CM, Bennett ED. High fat, low carbohydrate, enteral feeding lowers $\mathrm{PaCO} 2$ and reduces the period of ventilation in artificially ventilated patients. Intensive Care Med (1989) 15:290-5. doi: 10.1007/BF00263863

29. Thewissen JGM, Madar SI. Ankle morphology of the earliest cetaceans and its implications for the phylogenetic relations among ungulates. Syst Biol (1999) 48:21-30. doi:10.1080/106351599260418

30. Yeates L, Carlin KP, Baird M, VennWatson S, Ridgway S. Nitric oxide in the breath of bottlenose dolphins: effects of breath hold duration, feeding, and lung disease. Mar Mamm Sci (2013). doi:10.1111/ mms. 12037

31. Schivo M, Aksenov AA, Yeates LC, Pasamontes A, Davis CE. Diabetes and the metabolic syndrome: possibilities of a new breath test in a dolphin model. Front Endocrino (2013) 4:163. doi:10.3389/fendo. 2013.00163

32. Irving L, Scholander PF, Grinnell SW. The respiration of the porpoise, Tursiops truncatus. J Cell Comp Physiol (1941) 17:145-67. doi:10. 1002/jcp.1030170203

33. Schmidt-Nielsen K. Animal Physiology. Cambridge: Cambridge University Press (1975). 37 p.

34. Wislocki GB. On the structure of the lungs of the porpoise (Tursiops truncatus). Am J Anat (1929) 4:47-77. doi:10.1002/aja.1000440103

35. Ridgway SH. The bottlenosed dolphin in biomedical research. In: Gay WI editor. Methods of Animal Experimentation. (Vol. 3), New York: Academic Press (1968). p. 387-440.

36. Warden CJ, Warner LH. The sensory capacities and intelligence of dogs, with a report on the ability of the noted dog "fellow" to respond to verbal stimuli. $Q$ Rev Biol (1928) 3:1-28. doi:10.1086/ 394292

37. Kaminski J, Call J, Fischer J. Word learning in the domestic dog: evidence for "fast mapping". Science (2004) 304:1682-3. doi:10.1126/ science. 1097859

38. Pilley JW, Reid AK. Border collie comprehends object names as verbal referents. Behav Processes (2011) 86:184-95. doi:10.1016/j. beproc. 2010.11.007

39. Rossi AP, Ades C. A dog at the keyboard: using arbitrary signs to communicate requests. Anim Cogn (2008) 11:329-38. doi:10. 1007/s10071-007-0122-3

Conflict of Interest Statement: The author declares that the research was conducted in the absence of any commercial or financial relationships that could be construed as a potential conflict of interest. The Guest Associate Editor, Stephanie Venn-Watson declares that, despite being affiliated with the same institution as the author Sam Ridgway, the review process was handled objectively and no conflict of interest exists.

Received: 19 August 2013; paper pending published: 05 September 2013; accepted: 05 October 2013; published online: 16 December 2013.

Citation: Ridgway SH (2013) A mini review of dolphin carbohydrate metabolism and suggestions for future research using exhaled air. Front. Endocrinol. 4:152. doi: 10.3389/fendo.2013.00152

This article was submitted to Diabetes, a section of the journal Frontiers in Endocrinology.

Copyright (C) 2013 Ridgway. This is an open-access article distributed under the terms of the Creative Commons Attribution License (CC BY). The use, distribution or reproduction in other forums is permitted, provided the original author(s) or licensor are credited and that the original publication in this journal is cited, in accordance with accepted academic practice. No use, distribution or reproduction is permitted which does not comply with these terms. 